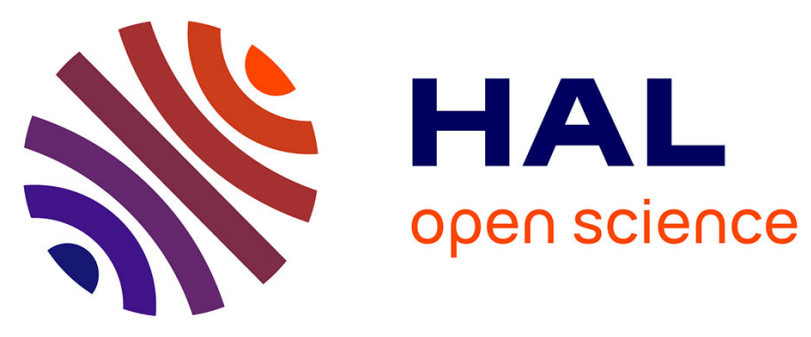

\title{
Does Pasteurized Donor Human Milk Efficiently Protect Preterm Infants Against Oxidative Stress?
}

Anna Parra-Llorca, María Gormaz, Ángel Sánchez-Illana, José David Piñeiro-Ramos, Maria Carmen Collado, Eva Serna, María Cernada, Antonio Nuñez-Ramiro, Amparo Ramón-Beltrán, Camille Oger, et al.

\section{To cite this version:}

Anna Parra-Llorca, María Gormaz, Ángel Sánchez-Illana, José David Piñeiro-Ramos, Maria Carmen Collado, et al.. Does Pasteurized Donor Human Milk Efficiently Protect Preterm Infants Against Oxidative Stress?. Antioxidants and Redox Signaling, 2019, 31 (11), pp.791-799. 10.1089/ars.2019.7821 . hal-02617154

\section{HAL Id: hal-02617154 https://hal.science/hal-02617154}

Submitted on 3 Jun 2021

HAL is a multi-disciplinary open access archive for the deposit and dissemination of scientific research documents, whether they are published or not. The documents may come from teaching and research institutions in France or abroad, or from public or private research centers.
L'archive ouverte pluridisciplinaire HAL, est destinée au dépôt et à la diffusion de documents scientifiques de niveau recherche, publiés ou non, émanant des établissements d'enseignement et de recherche français ou étrangers, des laboratoires publics ou privés. 


\title{
Does Pasteurized Donor Human Milk Efficiently Protect Preterm Infants Against Oxidative Stress?
}

\author{
Anna Parra-Llorca, ${ }^{1}$ María Gormaz, ${ }^{2}$ Ángel Sánchez-Illana, ${ }^{1}$ José David Piñeiro-Ramos, ${ }^{1}$ \\ Maria Carmen Collado, ${ }^{3}$ Eva Serna, ${ }^{4}$ María Cernada, ${ }^{2}$ Antonio Nuñez-Ramiro,, Amparo Ramón-Beltrán, ${ }^{2}$ \\ Camille Oger, ${ }^{5}$ Jean-Marie Galano, ${ }^{5}$ Claire Vigor, ${ }^{5}$ Thierry Durand, ${ }^{5}$ Julia Kuligowski,, and Máximo Vento ${ }^{1,2, *}$
}

\begin{abstract}
Pasteurized donor human milk (DHM) is the preferred alternative for infant nutrition when own mother's milk $(\mathrm{OMM})$ is unavailable. Whether DHM is an efficient means for protecting preterm infants from oxidative stress remains unknown. We quantified a panel of oxidative stress biomarkers in urine samples from preterm infants $(\leq 32$ weeks of gestation and a birth weight $\leq 1500 \mathrm{~g}$ ) receiving $\geq 80 \%$ of feeding volume as either DHM or OMM. The noninvasive in vivo assessment of oxidative stress showed no statistically significant difference between both groups at the time when full enteral nutrition $(150 \mathrm{~mL} / \mathrm{kg}$ body weight) was achieved and until hospital discharge. In addition, the changes of urinary biomarker levels with time were assessed. This is the first longitudinal study on oxidative stress levels in preterm infants fed with DHM in comparison with OMM. There is no statistically significant difference in urinary oxidative stress levels of preterm infants from both groups indicating that despite the effects of pasteurization, DHM is a valid alternative when OMM is not available. Based on the results, we raise the hypothesis that pasteurized DHM protects preterm infants from oxidative stress as good as OMM, and consequently, its use could prevent oxidative stress-related diseases. Antioxid. Redox Signal. 31, 791-799.
\end{abstract}

Keywords: preterm infant, full enteral feeding, oxidative stress, donor human milk (DHM), own mother's milk (OMM), biomarkers

\section{Introduction}

$\mathbf{P}$ REMATURE BIRTH IS associated with high mortality and morbidity in the neonatal period and long-term neurodevelopmental and sensorial sequel, thereby constituting a serious health problem worldwide. The incidence of prematurity ranges from $8 \%$ to $10 \%$ in Western countries but is considerably higher in low-income countries in which it is one of the leading causes of early neonatal death.

Preterm infants are frequently submitted to oxygen supplementation, parenteral nutrition, radiation, or phototherapy among other therapies that cause the generation of reactive oxygen species (ROS). ROS will contribute to the develop-

\section{Innovation}

A human milk (HM) diet protects preterm infants from oxidative stress, thereby preventing them from conditions associated with free radical attack and immature antioxidant defenses. Pasteurized donor human milk (DHM) is used for feeding preterm infants when own mother's milk $(\mathrm{OMM})$ is not available. Results demonstrate that regardless of pasteurization, DHM protects infants against oxidative stress in a similar way as OMM as reflected in levels of a comprehensive panel of oxidative stress biomarkers suitable for a noninvasive in vivo assessment. This underpins the importance of promoting HM banks that provide DHM for preterm infant nutrition in situations where OMM is not available at all or volume is insufficient.

\footnotetext{
${ }^{1}$ Neonatal Research Group, Health Research Institute La Fe, Valencia, Spain.

${ }^{2}$ Division of Neonatology, University and Polytechnic Hospital La Fe, Valencia, Spain.

${ }^{3}$ Department of Biotechnology, Institute of Agrochemistry and Food Technology, Spanish National Research Council (IATA-CSIC), Paterna, Spain.

${ }^{4}$ Department of Physiology, Faculty of Medicine, University of Valencia, Valencia, Spain.

${ }^{5}$ Institut des Biomolécules Max Mousseron, UMR 5247 CNRS, ENSCM, Université de Montpellier, Montpellier, France.

*Senior author.
} 
ment of severe conditions such as bronchopulmonary dysplasia, retinopathy of prematurity, or intraventricular hemorrhage among others (8).

Human milk (HM) is a complex biological fluid that fulfills nutritional and immunological requirements and favors the neurodevelopment of the newborn infant. It is therefore considered the gold standard for newborn nutrition (4). A large variety of nutritional and bioactive components present in HM such as oligosaccharides, microorganisms, cytokines, immune cells, lysozymes, and lactoferrin have an immunostimulant and protective role (5). In addition, HM also enhances the antioxidant defenses by providing enzymatic and nonenzymatic antioxidants. Thus, preterm infants fed with HM present lower levels of oxidative stress biomarkers than those fed with preterm infant formula milk (FM) (4).

Pasteurized donor human milk (DHM) is a valid alternative when own mother's milk (OMM) is unavailable. Human milk banks are dedicated to collecting milk from donor mothers, and process, store, and dispense it following stringent protocols for assuring hygiene. However, pasteurization and freezing may change the activity and concentration of several biological factors and biomolecules, including antioxidants (5).

Although there is evidence indicating that DHM offers nutritional and immunological advantages over FM, and DHM has been associated with a reduced incidence of necrotizing enterocolitis in preterm infants (9), it remains yet to be proven whether pasteurized DHM maintains an efficient in vivo antioxidant capacity.

We hypothesized that DHM and OMM equally protect preterm infants from oxidative stress. We launched a longitudinal, observational cohort study aiming to compare the antioxidant properties of DHM versus OMM reflected in levels of a panel of oxidative stress biomarkers previously validated in preterm urine $(6,7)$. We performed analytical determinations in preterm infants' urine samples collected between the initiation of full enteral feeding and hospital discharge.

\section{Results}

The flow diagram (Fig. 1) shows the number of eligible, disregarded, and finally included patients. From a total of 184 eligible preterm infants, 58 babies (34 in the OMM group and 24 in the DHM group) completed the study. Table 1 shows no differences in the demographic characteristics, as well as in the perinatal, clinical, and analytical variables or incidence of neonatal conditions related with prematurity between groups, matched according to the type of feeding.

Biomarkers that were not detected in $>75 \%$ of the samples (i.e., concentrations < limit of quantification [LOQ]) were excluded from the final data analysis. The results obtained from the determination of the remaining biomarkers of oxidative damage to DNA (8-oxo-2'-deoxyguanosine $/ 2^{\prime}$-deoxyguanosine $\left.[8 \mathrm{OHdG} / 2 \mathrm{dG}]\right)$, proteins (o-Tyr/Phe), and lipids (11 individual isoprostanoids and 5 total parameters), as well as 4 prostaglandins (PGs) and related substances in urine samples from preterm infants fed with OMM and DHM, are summarized in Table 2. Figure 2 shows standardized biomarker ratios found in urine samples from both study populations collected at different time points. No significant differences were found for any of the 22 detected biomarkers at the initiation of

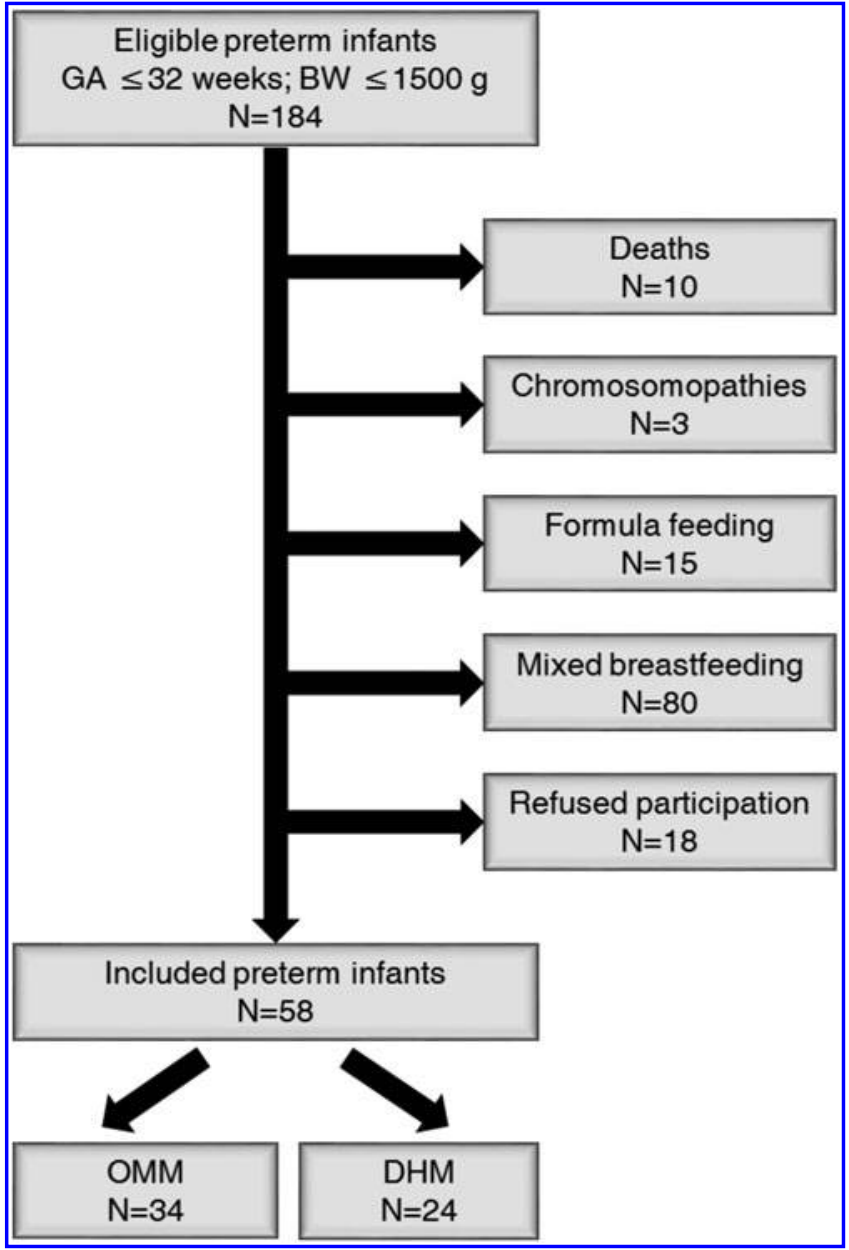

FIG. 1. Flow diagram of patient enrollment. BW, birth weight; GA, gestational age; DHM, donor human milk; OMM, own mother's milk.

full enteral nutrition as well as 1,2 , or 3 weeks thereafter ( $p$-value $>0.05$, Wilcoxon rank sum test).

To study the longitudinal evolution of oxidative stress biomarkers, median values and interquartile ranges of each detected biomarker in the whole study population (OMM and DHM) at different timings were assessed. Urinary levels of $8 \mathrm{OHdG} / 2 \mathrm{dG}, 11$ of 15 detected individual isoprostanoids and related substances, as well as total NeuroPs and total NeuroFs remained unchanged during the study period. However, as shown in Figure 3, the $o$-Tyr/Phe ratio, four individual isoprostanoids, total IsoPs, total IsoFs, and total dihomo-IsoFs significantly changed during the study period ( $p$-values $<0.05$, Wilcoxon rank sum test).

\section{Discussion}

Premature babies have an immature antioxidant defense system, and ROS have been linked to the development of relevant conditions such as bronchopulmonary dysplasia, retinopathy of prematurity, intraventricular and periventricular hemorrhage, or NEC, among others (8). HM contains an ample array of antioxidants with positive effects on oxidative stress-associated conditions. In a recent meta-analysis (9), it has been shown that an exclusive HM diet reduces the risk of bronchopulmonary dysplasia, compared with a diet 
Table 1. Perinatal Characteristics and Confounders During Hospitalization in the Neonatal Intensive Care Unit of Preterm Infants $\leq 32$ Weeks Gestation or $\leq 1500$ g Fed Own Mother's Milk or Donor Human Milk

\begin{tabular}{|c|c|c|c|}
\hline Parameter & $O M M(\mathrm{n}=34)$ & $D H M(\mathrm{n}=24)$ & p-Value \\
\hline GA weeks, median (95\% CI) & $28(27-29)$ & $29(28-30)$ & 0.06 \\
\hline Birth weight $(\mathrm{g})$, mean (SD) & $1200(313)$ & $1266(270)$ & 0.4 \\
\hline Antenatal steroids full course, $n(\%)$ & $31(91)$ & $21(88)$ & 0.5 \\
\hline Pre-eclampsia, $n(\%)$ & $5(15.7)$ & 7 (29) & 0.2 \\
\hline Chorioamnionitis, $n(\%)$ & $8(24)$ & $2(8)$ & 0.12 \\
\hline \multicolumn{4}{|l|}{ Type of delivery, $n(\%)$} \\
\hline Vaginal & $16(47)$ & $11(46)$ & \multirow[t]{2}{*}{0.6} \\
\hline C-section & $18(53)$ & $13(54)$ & \\
\hline Twins, $n(\%)$ & $6(18)$ & $7(29)$ & 0.2 \\
\hline Apgar 1 min, median (95\% CI) & $7(6-9)$ & $8(7-10)$ & 0.3 \\
\hline Apgar 5 min, median $(95 \% \mathrm{CI})$ & $9(8-10)$ & $9(8-10)$ & 1.0 \\
\hline Umbilical artery blood gases, mean (SD) & $7.29(0.12)$ & $7.27(0.08)$ & 0.4 \\
\hline Umbilical vein blood gases, mean (SD) & $7.3(0.07)$ & $7.3(0.06)$ & 0.06 \\
\hline Respiratory distress syndrome, $n(\%)$ & $13(38)$ & $5(21)$ & 0.13 \\
\hline Apneic syndrome, $n(\%)$ & $30(88)$ & $18(75)$ & 0.2 \\
\hline Persistent ductus arteriosus, $n(\%)$ & $14(41)$ & $6(25)$ & 0.2 \\
\hline Antibiotic therapy, $n(\%)$ & $13(38)$ & $9(38)$ & 0.6 \\
\hline Bronchopulmonary dysplasia, $n(\%)$ & $2(6)$ & $1(4)$ & 0.6 \\
\hline Retinopathy of prematurity, $n(\%)$ & $1(4)$ & $0(0)$ & 0.4 \\
\hline Intraventricular hemorrhage, $n(\%)$ & $3(9)$ & $2(8)$ & 0.5 \\
\hline Nosocomial sepsis, $n(\%)$ & $0(0)$ & $0(0)$ & 1.0 \\
\hline
\end{tabular}

CI, confidence interval; GA, gestational age.

Table 2. Ranges of the Measured Molecular Biomarkers in Own Mother's Milk and Donor Human Milk Samples Expressed as Median and Third and First Quartiles InDEPENDENTLy of THE SAMPLing TIME

\begin{tabular}{|c|c|c|}
\hline \multirow[b]{2}{*}{ Biomarker } & $O M M$ & \multirow{2}{*}{$\frac{D H M}{\text { Median }\left(Q_{3}-Q_{1}\right)}$} \\
\hline & Median $\left(Q_{3}-Q_{1}\right)$ & \\
\hline DNA oxidation $(8 \mathrm{OHdG} / 2 \mathrm{dG})$ & $0.06(0.12-0.02)$ & $0.03(0.08-0.02)$ \\
\hline Protein oxidation (o-Tyr/Phe) & $0.044(0.062-0.003)$ & $0.003(0.042-0.001)$ \\
\hline $5(R S)-5-\mathrm{F}_{2 \mathrm{t}}-\mathrm{IsoP}\left[\mathrm{nmol} / \mathrm{g}_{\text {creat }}\right]$ & $12.7(20.7-9.1)$ & $9.6(14.8-6.8)$ \\
\hline 2,3-dinor-15- & $23.7(35.3-15.8)$ & $22.3(31.0-12.3)$ \\
\hline $\mathrm{F}_{2 \mathrm{t}}$-IsoP $\left[\mathrm{nmol} / \mathrm{g}_{\text {creat }}\right]$ & & \\
\hline $4(R S)-4-\mathrm{F}_{4 \mathrm{t}}-\mathrm{NeuroP}\left[\mathrm{nmol} / \mathrm{g}_{\text {creat }}\right]$ & $6.3(10.0-2.8)$ & $5.1(9.9-1.4)$ \\
\hline 10-epi-10- $\mathrm{F}_{4 \mathrm{t}}-\mathrm{NeuroP}\left[\mathrm{nmol} / \mathrm{g}_{\text {creat }}\right]$ & $0.6(1.0-0.3)$ & $0.8(1.6-0.4)$ \\
\hline $10-\mathrm{F}_{4 \mathrm{t}}-$ NeuroP $\left[\mathrm{nmol} / \mathrm{g}_{\text {creat }}\right]$ & $0.7(1.1-0.4)$ & $1.1(1.4-0.6)$ \\
\hline $14(R S)-14-\mathrm{F}_{4 \mathrm{t}}-\mathrm{NeuroP}\left[\mathrm{nmol} / \mathrm{g}_{\text {creat }}\right]$ & $7.7(12.3-5.0)$ & $6.9(13.8-2.8)$ \\
\hline $17-\mathrm{F}_{2 \mathrm{t}}$-dihomo-IsoP $\left[\mathrm{nmol} / \mathrm{g}_{\text {creat }}\right]$ & $1.2(2.6-0.3)$ & $2.2(3.0-0.5)$ \\
\hline ent-7(RS)-7- $\mathrm{F}_{2 \mathrm{t}}$-dihomo-IsoP [nmol/g $\left.\mathrm{g}_{\text {creat }}\right]$ & $1.1(1.8-0.8)$ & $1.2(1.9-0.6)$ \\
\hline $17(R S)-10$-epi-SC- $\Delta^{15}$-11-dihomo-IsoF [nmol/g $\left.g_{\text {creat }}\right]$ & $2.8(5.0-0.9)$ & $4.0(6.6-2.4)$ \\
\hline 1a,1b-dihomo-PGF ${ }_{2 \alpha}\left[\mathrm{nmol} / \mathrm{g}_{\text {creat }}\right]$ & $4.4(7.3-3.0)$ & $5.2(6.6-3.9)$ \\
\hline $15-\mathrm{F}_{2 \mathrm{t}}$-IsoP $\left[\mathrm{nmol} / \mathrm{g}_{\text {creat }}\right]$ & $2.8(4.6-1.5)$ & $1.5(3.2-0.4)$ \\
\hline $11 \beta-\mathrm{PGF}_{2 \alpha}\left[\mathrm{nmol} / \mathrm{g}_{\text {creat }}\right]$ & $3.4(5.4-1.3)$ & $3.0(5.0-0.3)$ \\
\hline $15-e p i-15-\mathrm{F}_{2 \mathrm{t}}$-IsoP $\left[\mathrm{nmol} / \mathrm{g}_{\text {creat }}\right]$ & $12.4(22.1-7.2)$ & $7.5(10.9-4.0)$ \\
\hline 6-keto-PGF ${ }_{1 \alpha}\left[\mathrm{nmol} / \mathrm{g}_{\text {creat }}\right]$ & $0.8(1.7-0.3)$ & $0.7(1.8-0.3)$ \\
\hline $\mathrm{PGF}_{2 \alpha}\left[\mathrm{nmol} / \mathrm{g}_{\text {creat }}\right]$ & $21.2(28.1-15.8)$ & $16.0(21.2-1.5)$ \\
\hline NeuroFs [p.d.u.] & $140.0(180.2-111.8)$ & $146.1(186.2-116.6)$ \\
\hline IsoFs [p.d.u.] & $71.2(96.9-56.0)$ & $64.8(83.2-55.2)$ \\
\hline NeuroPs [p.d.u.] & $628.3(920.0-366.8)$ & $379.7(642.1-245.0)$ \\
\hline IsoPs [p.d.u.] & $233.8(291.3-155.0)$ & $214.1(273.8-75.1)$ \\
\hline Dihomo-IsoFs [p.d.u.] & $173.4(300.5-57.8)$ & $154.2(232.9-109.0)$ \\
\hline
\end{tabular}

The number of samples used was 101 and 47 for OMM and DHM, respectively, except for DNA oxidation and protein oxidation, where it was 93 and 43.

DHM, donor human milk; OMM, own mother's milk. 


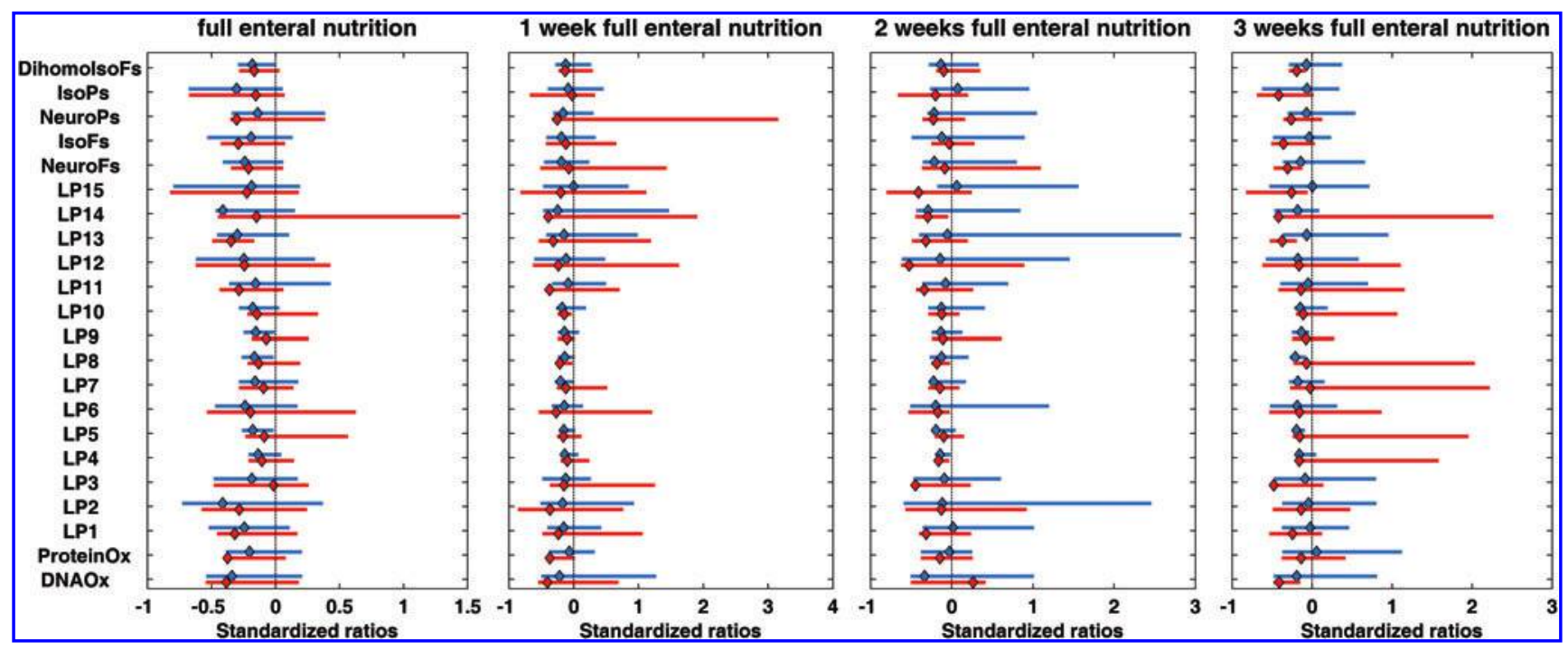

FIG. 2. Median values (diamonds) and percentile 10 to 90 (straight line) of standardized biomarker levels found in urine samples from preterm infants fed with OMM (blue) and DHM (red) at the moment of achieving full enteral nutrition and 1, 2 , and 3 weeks thereafter. ProteinOx $=o$-Tyr/Phe; DNAOx $=80 H d G / 2 d G ;$ LP1 $=5(\mathrm{RS})-5-\mathrm{F}_{2 \mathrm{t}}$-IsoP; LP2 $=15-$-epi-2,3-dinor-15-

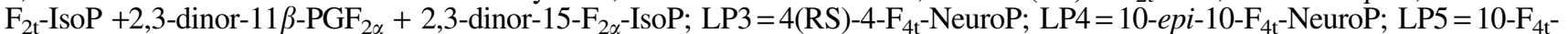

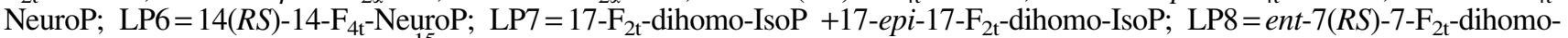
IsoP; LP9 = 17(RS)-10-epi-SC- $\Delta^{15}$-11-dihomo-IsoF; LP10=1a,1b-dihomo PGF $_{2 \alpha} ; \quad$ LP11 $=15-\mathrm{F}_{2 \mathrm{t}}$-IsoP; $_{\text {LP12 }}=11 \beta$-PGF $2 \alpha$; $\mathrm{LP} 13=15-$ epi-15- $\mathrm{F}_{2 \mathrm{t}}-\mathrm{IsoP} ; \mathrm{LP} 14=6-\mathrm{keto}^{-\mathrm{PGF}_{1 \alpha}} ; \mathrm{LP} 15=\mathrm{PGF}_{2 \alpha}$. Color images are available online.

with FM and/or bovine milk-based fortifier (risk ratio 0.80 , $95 \%$ confidence interval $0.68-0.95$ ). Moreover, feeding raw OMM, compared with feeding pasteurized OMM, is also protective against this chronic lung disease.

When OMM is unavailable, premature infants $<32$ weeks of gestation are fed with DHM. Whereas previous studies showed that premature infants fed with HM presented lower levels of metabolites derived from hydroxyl damage to proteins and DNA in urine than those fed with FM (4), the potential of pasteurized DHM to protect against oxidative stress and related pathologies remains unclear.

In vivo assessment of oxidative damage can be carried out by the detection of specific biomarkers in biological fluids that reflect damage to proteins, DNA, or lipids (8). Liquid chromatography-tandem mass spectrometry (LC-MS/MS) methods for the detection of biomarkers of oxidative damage to proteins and DNA (3), as well as lipids $(6,7)$ in noninvasively obtained urine samples, have been validated following stringent requirements of the FDA. Moreover, reference ranges of total parameters of lipid peroxidation by-products in very preterm infants evolving without significant clinical conditions in the postnatal period have been reported $(6,7)$.

Preterm infants included in this study were in good general condition and some of the measured biomarkers were found to be below the LOQ in the collected urine samples. For instance, biomarkers of myeloperoxidase action (3-Cltyrosine/p-tyrosine [3-Cl-Tyr/p-Tyr] and 3-nitrotyrosine [3$\mathrm{NO}_{2}$-Tyr $] / p$-Tyr) were not detected in this study, indicating a low proinflammatory status in this population of preterm infants. This finding is in agreement with previous studies where low quantification frequencies in preterm urine samples were reported for $m$-Tyr, 3-Cl-Tyr, and 3-NO $\mathrm{NO}_{2}$-Tyr (3). In addition, the use of highly sensitive LC-MS/MS platforms for the measurement of lipid peroxidation biomarkers allowed for the detection of a majority of measured isoprostanoids and related substances (15 out of 21) and total lipid peroxidation parameters (5 out of 6 ) in preterm infant's urine samples. We could speculate that the absence of some lipid peroxidation biomarkers might indicate relatively low levels of oxidative stress and a lack of associated damage to fatty acids. Alternatively, some isoprostanoids might have been metabolized or excreted at other than the studied time points.

We did not find statistically significant differences in a total of 22 biomarkers present at quantifiable levels in samples from infants consuming OMM and DHM at different time points that covered from achievement of full enteral nutrition to hospital discharge (Fig. 2). It has been described that Holder pasteurization alters some properties of OMM, and alternative systems of pasteurization are being studied to preserve more milk components such as ultraviolet-C irradiation, high pressure, or high temperature short time (heating at $72^{\circ} \mathrm{C}$ for $10-15 \mathrm{~s}$ ). However, other biomolecules with an active role in the protection against free radical such as vitamins and oligosaccharides are preserved during heat treatment (5). Results presented in this study support that despite the detrimental effect of pasteurization on some of the antioxidant components of HM, newborns receiving DHM are equally protected against free radical-associated damage to macromolecules as newborns fed with OMM.

Figure 3 shows that some biomarker levels vary as a function of sampling time. This is a very important observation providing valuable information for the design of future studies aiming at the detection of those biomarkers in preterm infant urine samples. As earlier reported $(6,7)$, the excretion profiles of isoprostanoids may be different depending on the studied compound family. 


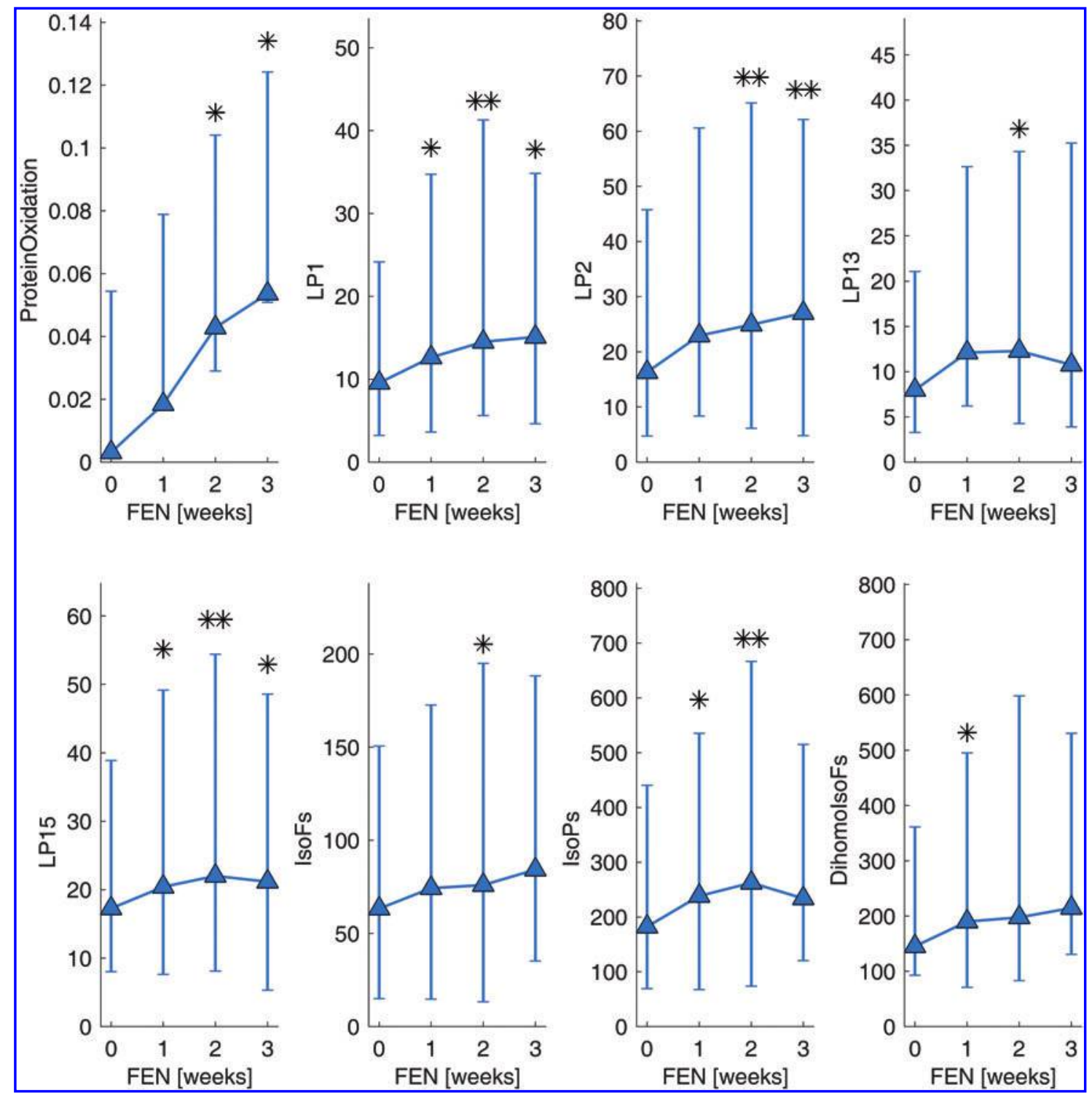

FIG. 3. Longitudinal evolution of biomarker levels with time. ProteinOx $=o$-Tyr $/ \mathrm{Phe}$; LP1 $=5(\mathrm{RS})-5-\mathrm{F}_{2 \mathrm{t}}-\mathrm{IsoP} ; \mathrm{LP} 2=15-$

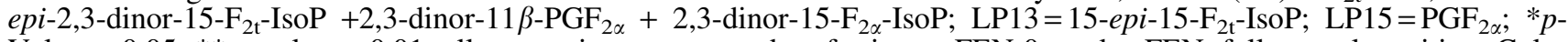
Values $<0.05$; ** $p$-values $<0.01$; all comparisons were made referring to FEN 0 weeks. FEN, full enteral nutrition. Color images are available online.

A limitation of the present study is the small sample size. Given the policy of promoting the use of OMM in the neonatal intensive care unit (NICU), access to a study population exclusively fed with DHM over several weeks is highly difficult as DHM is typically provided only to complete the requirements of enteral feed until enough OMM is available to satisfy the infant's demand. The analysis of noninvasive urine samples allowed to study preterm infants and enabled longitudinal observations without performing repeated painful invasive procedures. However, some of the biomarkers could not be quantified even though highly sensitive and dedicated analytical procedures were used. Another shortcoming is the lack of information on the effect of pasteurization on HM used in this study, including the total antioxidant capacity of OMM and DHM, as well as levels of HM compounds that are of known importance for the protection against oxidative stress.
There is no statistically significant difference in urinary oxidative stress levels of preterm infants fed with DHM in comparison with OMM. This indicates that DHM provided by a milk bank is a good alternative when OMM is not available. Despite pasteurization, DHM offers similar protection to oxidative stress in preterm infants when compared with OMM.

\section{Notes}

\section{Study design and ethics}

A prospective, longitudinal, observational cohort study, including consecutively admitted preterm infants born $\leq 32$ weeks of gestation and with a birth weight $\leq 1500 \mathrm{~g}$ in the Division of Neonatology of the University and Polytechnic Hospital La Fe (Valencia, Spain), was conducted during a 12month period. The study protocol was approved by the Ethics 
Committee for Biomedical Research (approval number (\#2015/0371) and informed consent was obtained from parents or legal representatives.

\section{Population}

Table 3 shows inclusion and exclusion criteria. Thirty-four patients fed with OMM and 24 patients fed with DHM admitted to the NICU were enrolled by a designated research associate (trained neonatologist). Our feeding protocol strongly supports breastfeeding and offers DHM as a supplement to preterm infants born $\leq 32$ weeks of gestation and/or $\leq 1500 \mathrm{~g}$ birth weight, if necessary. DHM from the milk bank is administered after being treated with Holder pasteurization $\left(62.5^{\circ} \mathrm{C}\right.$ for $\left.30 \mathrm{~min}\right)$ to inactivate viral and bacterial agents, following the guidelines of most HM banks (5). Microbiological and nutritional tests are performed to check milk suitability. Subsequently, pasteurized milk is aliquoted and frozen at $-20^{\circ} \mathrm{C}$ until its administration.

Inclusion criteria requested that the intake of OMM or DHM represented $\geq 80 \%$ of the total volume when full enteral nutrition $(150 \mathrm{~mL} / \mathrm{kg}$ body weight) was achieved (Table 3 ). The nutritional intake was prospectively monitored but never modified for this observational study. Demographic characteristics and perinatal, clinical, and analytical variables, as well as the incidence of neonatal conditions related with prematurity, were recorded.

\section{Urine sample collection}

Figure 4 gives an overview of the sample collection process. Urine samples were collected after achieving full enteral nutrition and once per week thereafter until hospital discharge. Urine was collected using sterile cotton pads placed in the diaper. Cotton pads were collected after $1 \mathrm{~h}$ and squeezed with a syringe. The process was repeated until collecting a minimum of $1 \mathrm{~mL}$. Urine samples were aliquoted (one aliquot for each analytical method) to avoid freezethawing cycles and stored at $-80^{\circ} \mathrm{C}$ until analysis.

TABle 3. InClusion ANd EXCluSion CRITERIA of Preterm Infants $\leq 32$ WeEKS/ $\leq 1500$ g Receiving Own Mother's Milk or Donor Human Milk DURING HOSPITALIZATION

\begin{tabular}{|c|c|}
\hline Inclusion criteria & Exclusion criteria \\
\hline $\begin{array}{l}\mathrm{BW} \leq 1500 \mathrm{~g} \text { and } \mathrm{GA} \leq 32 \\
\text { weeks }\end{array}$ & $\begin{array}{l}\text { GA }>32 \text { weeks or BW } \\
>1500 \mathrm{~g}\end{array}$ \\
\hline $\begin{array}{l}\text { Enteral intake ( } \geq 150 \mathrm{~mL} / \\
\mathrm{kg} / \text { day })\end{array}$ & $\begin{array}{l}\text { Parents refuse to participate/ } \\
\text { sign informed consent. }\end{array}$ \\
\hline $\begin{array}{l}\text { The principal nutrient } \\
\text { received (OMM, DHM) is } \\
\geq 80 \% \text { of the total intake }\end{array}$ & Mixed breastfeeding \\
\hline $\begin{array}{l}\text { DHM from a maximum } \\
\text { of two donors to one } \\
\text { premature infant }\end{array}$ & Chromosomopathies \\
\hline $\begin{array}{l}\text { No additional treatments that } \\
\text { could alter the microbiome } \\
\text { (e.g., probiotics) or } \\
\text { oxidative status } \\
\text { (e.g., vitamin } \mathrm{C}, \mathrm{A}, \mathrm{E})\end{array}$ & $\begin{array}{l}\text { Major malformations or } \\
\text { surgery of the digestive } \\
\text { tract }\end{array}$ \\
\hline
\end{tabular}

BW, birth weight.

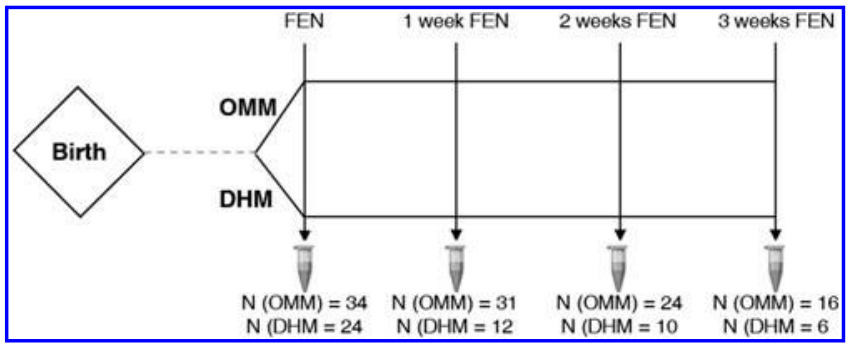

FIG. 4. Flow diagram of the sample collection process.

\section{Urine analysis}

Standards and reagents. LC-MS grade solvents (methanol $\mathrm{CH}_{3} \mathrm{OH}$, ethanol, heptane, and acetonitrile $\mathrm{CH}_{3} \mathrm{CN}$ ) were purchased from J.T. Baker (Phillipsburg, NJ). Formic acid $(98 \%)$ and ethyl acetate (analytical grade) were from Panreac (Barcelona, Spain). Milli-Q grade water (>18.2 M 2 ) from a Merck Millipore (Darmstadt, Germany) purification system was used. $\beta$-glucuronidase from Escherichia coli was from Sigma-Aldrich (St. Louis, MO).

Standards of $o-, m-$, and $p$-tyrosine ( $o-, m-$, and $p$-Tyr), 3-ClTyr, 3-NO $-\mathrm{NO}_{2}$-Tyr, phenylalanine (Phe), $8 \mathrm{OHdG}$ and $2 \mathrm{dG}(>96 \%$ w/w purity) were obtained from Sigma-Aldrich. Deuterated phenylalanine $\left(\mathrm{Phe}-\mathrm{D}_{5}\right)$ was purchased from $\mathrm{CDN}$ Isotopes (Pointe-Claire, Canada) and 8-oxo- $2^{\prime}$-deoxyguanosine- ${ }^{13} \mathrm{C}^{15} \mathrm{~N}_{2}$ (8OHdG- $\left.{ }^{13} \mathrm{C}^{15} \mathrm{~N}_{2}\right)$ and $2^{\prime}$-deoxyguanosine- ${ }^{13} \mathrm{C}^{15} \mathrm{~N}_{2}\left(2 \mathrm{dG}-{ }^{13} \mathrm{C}^{15}\right.$ $\mathrm{N}_{2}$ ) were from Toronto Research Chemicals (Toronto, Canada). Purities of isotopically labeled compounds were $>98 \% \mathrm{w} / \mathrm{w}$.

Commercially available IsoPs (2,3-dinor- $15-\mathrm{F}_{2 \mathrm{t}}$-IsoP, 15 keto-15- $\mathrm{E}_{2 \mathrm{t}}$-IsoP, 15-keto-15- $\mathrm{F}_{2 \mathrm{t}}$-IsoP, 15-epi-15- $\mathrm{F}_{2 \mathrm{t}}$-IsoP, $15-\mathrm{E}_{2 \mathrm{t}}$-IsoP, $15-\mathrm{F}_{2 \mathrm{t}}$-IsoP), PGs ( $\mathrm{PGE}_{2}, \mathrm{PGF}_{2 \alpha}, 2,3$-dinor- $11 \beta$ $\mathrm{PGF}_{2 \alpha}, 11 \beta$-PGF $2 \alpha, 6$-keto-PGF $1 \alpha$ ), and dihomo-PG (1a, $1 \mathrm{~b}$ dihomo-PGF $\mathrm{PG}_{2 \alpha}$ ) with purities $\geq 95 \%$ were obtained from Cayman Chemical Company (Ann Arbor, MI), as well as deuterated compounds $\left(\mathrm{PGF}_{2 \alpha}-\mathrm{D}_{4}\right.$ and $\left.15-\mathrm{F}_{2 \mathrm{t}}-\mathrm{IsoP}-\mathrm{D}_{4}\right)$ with purities $\geq 98 \%$ and incorporation $\geq 99 \%$ deuterated form $\left(\mathrm{D}_{1}-\right.$ $\left.\mathrm{D}_{4}\right) ;<1 \%{ }^{1} \mathrm{H}$. Other analytical standards used were synthesized at the Institut des Biomolecules Max Mousseron (Montpellier, France) according to previously published procedures, with purities $\geq 99 \%$ and all physical data confirming the new structures reported in previous articles $(1,2)$, including $\mathrm{F}_{2}$-IsoPs (5- $\mathrm{F}_{2 \mathrm{t}}$-IsoP, 5-epi-5- $\mathrm{F}_{2 \mathrm{t}}$-IsoP, 15-epi-2,3-dinor-15- $\mathrm{F}_{2 \mathrm{t}}$-IsoP),

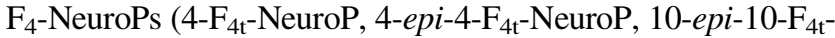
NeuroP, 10- $\mathrm{F}_{4 \mathrm{t}}-$ NeuroP, 14(RS)-14- $\mathrm{F}_{4 \mathrm{t}}-$ NeuroP), $\mathrm{F}_{4}-\mathrm{NeuroF}$ $\left(4(R S)-\mathrm{ST}-\Delta^{5}-8-\mathrm{NeuroF}\right), \mathrm{F}_{2}$-dihomo-IsoPs (17- $\mathrm{F}_{2 \mathrm{t}}$-dihomoIsoP, 17-epi-17- $\mathrm{F}_{2 \mathrm{t}}$-dihomo-IsoP, ent-7(RS)-7- $\mathrm{F}_{2 \mathrm{t}}$-dihomo-IsoP), and $\mathrm{F}_{2}$-dihomo-IsoFs (17(RS)-10-epi-SC- $\Delta^{15}$-11-dihomoIsoF, 7(RS)-ST- $\Delta^{8}$-11-dihomo-IsoF).

Determination of urinary biomarkers of oxidative damage to DNA and proteins. The determination of biomarkers of oxidative damage to DNA and proteins was performed following a previously validated ultraperformance liquid chromatography-tandem mass spectrometry (UPLC-MS/MS) method (3). Briefly, samples were thawed on ice, homogenized for $5 \mathrm{~s}$, and centrifuged at $15,000 \mathrm{~g}$ for $10 \mathrm{~min}$ at $4^{\circ} \mathrm{C}$. Ninety microliters of supernatant was added to $10 \mu \mathrm{L}$ of internal standard (IS) solution containing $2 \mu \mathrm{M}$ of Phe- $\mathrm{D}_{5}$, $2 \mathrm{dG}-{ }^{13} \mathrm{C}^{15} \mathrm{~N}_{2}$, and $80 \mathrm{HdG}^{13}{ }^{13} \mathrm{C}^{15} \mathrm{~N}_{2}$ in formic acid $(0.1 \% \mathrm{v} / \mathrm{v})$.

Samples were analyzed using an Acquity-Xevo TQ system from Waters (Milford, MA) operating in a positive 


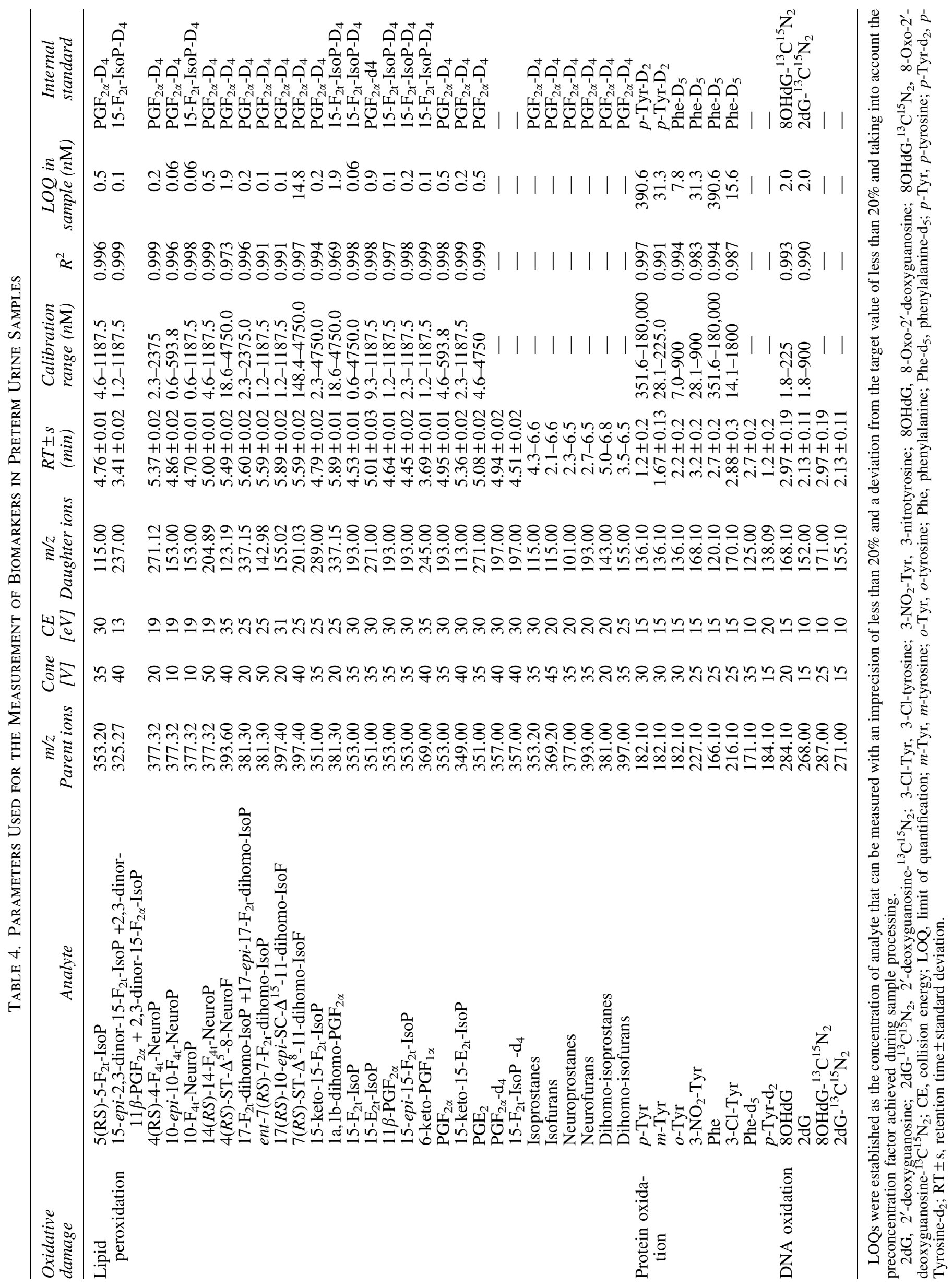


electrospray ionization $\left(\mathrm{ESI}^{+}\right)$mode. Separations were performed using an Acquity UPLC BEH C18 reversed-phase column $(2.1 \times 50 \mathrm{~mm}, 1.7 \mu \mathrm{m})$ from Waters and a $\mathrm{CH}_{3} \mathrm{OH}$ ( $0.05 \% \mathrm{v} / \mathrm{v}$ formic acid) $: \mathrm{H}_{2} \mathrm{O}(0.05 \% \mathrm{v} / \mathrm{v}$ formic acid) binary gradient. For quantification of $8 \mathrm{OHdG}, 2 \mathrm{dG}, o$-Tyr, $m$-Tyr, $3-$ Cl-Tyr, 3- $\mathrm{NO}_{2}$-Tyr, $p$-Tyr, and Phe in urine, signals from samples were compared with signals of an external calibration line. Calibration standards were obtained from serial dilutions of a working solution containing pure analytical standards. Linear response curves were calculated using pTyr-D 2 , Phe-D 5 , 2dG- ${ }^{13} \mathrm{C}^{15} \mathrm{~N}_{2}$, and $8 \mathrm{OHdG}^{-13} \mathrm{C}^{15} \mathrm{~N}_{2}$ as ISs. Parameters used for the measurement of different metabolites are summarized in Table 4. A quality control (QC) sample was prepared by mixing $5 \mu \mathrm{L}$ of each sample. Aliquots of the QC sample were prepared as described for urine samples and intercalated every 15 samples in the measurement sequence for monitoring the instrument's performance. For comparisons between samples, the following metabolite ratios were determined: $8 \mathrm{OHdG} / 2 \mathrm{dG}, o$-Tyr/Phe, $m$-Tyr/Phe, 3-ClTyr/p-Tyr, and 3-NO ${ }_{2}$-Tyr/p-Tyr.

Determination of free radical-mediated lipid peroxidation biomarkers in urine. Individual and total free radicalmediated lipid peroxidation biomarkers were determined in urine samples using previously validated UPLC-MS/MS methods $(6,7)$. In summary, urine samples were thawed on ice and homogenized followed by the addition of $10 \mu \mathrm{L}$ of $\beta$ glucuronidase solution $\left(10 \mathrm{mg} \mathrm{mL}^{-1}\right)$ to $600 \mu \mathrm{L}$ of sample and incubated at $37^{\circ} \mathrm{C}$ for $90 \mathrm{~min}$. After incubation, $300 \mu \mathrm{L}$ of IS solution $\left(\mathrm{PGF}_{2 \alpha}-\mathrm{D}_{4}\right.$ and $\left.15-\mathrm{F}_{2 \mathrm{t}}-\mathrm{IsoP}_{-} \mathrm{D}_{4}, 0.2 \mu M\right)$ in $\mathrm{H}_{2} \mathrm{O}$ $(0.1 \% \mathrm{v} / \mathrm{v}$ formic acid, $\mathrm{pH}=3): \mathrm{CH}_{3} \mathrm{OH}(85: 15, \mathrm{v} / \mathrm{v})$ was added, homogenized, and centrifuged at $10,000 \mathrm{~g}$ for $10 \mathrm{~min}$ at $4^{\circ} \mathrm{C}$. For cleanup and preconcentration, solid-phase extraction (SPE) using Discovery ${ }^{\circledR}$ DSC-18 SPE 96-well plates (Sigma-Aldrich) was carried out. SPE cartridges were conditioned with $1 \mathrm{~mL}$ of $\mathrm{CH}_{3} \mathrm{OH}$ followed by rinsing with $1 \mathrm{~mL}$ of $\mathrm{H}_{2} \mathrm{O}$. The diluted sample was loaded onto the SPE plate followed by washing with $500 \mu \mathrm{L}$ of $\mathrm{H}_{2} \mathrm{O}$ and $500 \mu \mathrm{L}$ of heptane. Elution of biomarkers was carried out using $4 \times 100 \mu \mathrm{L}$ of ethyl acetate. Recovered sample extracts were evaporated and dissolved in $60 \mu \mathrm{L}$ of $\mathrm{H}_{2} \mathrm{O}(0.1 \% \mathrm{v} / \mathrm{v}$ formic acid, $\mathrm{pH} 3): \mathrm{CH}_{3} \mathrm{OH}(85: 15 \mathrm{v} / \mathrm{v})$.

Samples were analyzed using an Acquity-Xevo TQS system from Waters operating in an $\mathrm{ESI}^{-}$mode using a Waters BEH C18 reversed-phase column $(2.1 \times 100 \mathrm{~mm}, 1.7 \mu \mathrm{m})$ and a binary $\mathrm{H}_{2} \mathrm{O}(0.1 \% \mathrm{v} / \mathrm{v}$ formic acid $): \mathrm{CH}_{3} \mathrm{CN}(0.1 \% \mathrm{v} / \mathrm{v}$ formic acid) gradient. For biomarker quantification in urine samples, an external calibration approach and the same quality control measures, as described for the previous method, were used. In case of total parameters (total IsoPs, IsoFs, NeuroPs, NeuroFs, dihomo-IsoPs, and dihomo-IsoFs), detection was carried out as previously described (7) and recently developed for dihomo-IsoPs and dihomo-IsoFs (6). Relative signal intensities normalized using the IS signal instead of absolute concentrations were determined to circumvent the lack of pure analytical standards. Total parameters were considered when the area was greater than nine times the signal of a blank. The measurement parameters used for the studied biomarkers are summarized in Table 4.

Biomarker concentrations and total parameter responses were normalized by creatinine that was quantified by the modified Jaffe method implemented in the Detect $\mathrm{X}^{\circledR}$ urinary creatinine detection kit from Arbor Assays (Ann Arbor, MI) following the manufacturer's instructions.

\section{Statistics}

LC-MS/MS data were acquired and processed using MassLynx 4.1 and QuanLynx 4.1 (Waters, Milford, MA), respectively. Biomarker concentrations found below the LOQ were replaced by $0.5 \times$ LOQ before data analysis. Data analysis was carried out in MATLAB 2017a from MathWorks (Natick, MA) and SPSS 17.0 (SPSS, Inc., Chicago, IL). Categorical variables were compared using Pearson's chi-squared test $(\alpha=0.05)$. Kolmogorov-Smirnov analysis was performed to test the normal distribution of data. Continuous variables were expressed as mean \pm standard deviation or medians with interquartile range depending on underlying distributions, and comparisons were carried out using the Student's $t$-test $(\alpha=5 \%)$ for data following a normal distribution or alternatively the Wilcoxon rank sum test $(\alpha=5 \%)$.

\section{Acknowledgments}

The authors express their gratitude to the mothers and their newborns who participated in the study. They also thank the Servicio de Soporte a la Investigación Experimental (SCSIE) of the University of Valencia (Spain). J.K. received salary support from a Miguel Servet grant (CP16/00034), A.S.-I. from a PFIS grant (FI16/000380), and A.P.-L. from a Rio Hortega grant (CM18/00165), all provided by the Instituto Carlos III (Ministry of Economy and Competitiveness, Spain). This work was partly funded through the Instituto Carlos III (grant number PI17/00127 and PI17/0131), the European Society for Paediatric Research (Young Investigator Start-up 2016 grant), and the Spanish Maternal, Neonatal, and Developmental Network SAMID RETICS (RD16/0022/0001) funded by the PN 2018-2021 (Spain), ISCIII-Sub-Directorate General for Research Assessment and Promotion, and the European Regional Development Fund (FEDER).

\section{Author Disclosure Statement}

The authors declare that the research was conducted in the absence of any commercial or financial relationships that could be construed as a potential conflict of interest.

\section{References}

1. de la Torre A, Yiu LY, Attilio M, Alexandre G, Valérie B-P, Thierry D, Camille O, Chung-Yung LJ, and Jean-Marie G. Total syntheses and in vivo quantitation of novel neurofuran and dihomo-isofuran derived from docosahexaenoic acid and adrenic acid. Chemistry 21: 2442-2446, 2014.

2. Guy A, Oger C, Heppekausen J, Signorini C, De Felice C, Fürstner A, Durand T, and Galano J-M. Oxygenated metabolites of n-3 polyunsaturated fatty acids as potential oxidative stress biomarkers: total synthesis of 8-F3t-IsoP, 10F4t-NeuroP and [D4]-10-F4t-NeuroP. Chemistry 20: 63746380, 2014.

3. Kuligowski J, Torres-Cuevas I, Quintás G, Rook D, van Goudoever JB, Cubells E, Asensi M, Lliso I, Nuñez A, Vento M, and Escobar J. Assessment of oxidative damage to 
proteins and DNA in urine of newborn infants by a validated UPLC-MS/MS approach. PLoS One 9: e93703, 2014.

4. Ledo A, Arduini A, Asensi MA, Sastre J, Escrig R, Brugada M, Aguar M, Saenz P, and Vento M. Human milk enhances antioxidant defenses against hydroxyl radical aggression in preterm infants. Am J Clin Nutr 89: 210-215, 2009.

5. Peila C, Moro GE, Bertino E, Cavallarin L, Giribaldi M, Giuliani F, Cresi F, and Coscia A. The effect of holder pasteurization on nutrients and biologically-active components in donor human milk: a review. Nutrients 8: pii: E477, 2016.

6. Sánchez-Illana Á, Shah V, Piñeiro-Ramos JD, Di Fiore JM, Quintás G, Raffay TM, MacFarlane PM, Martin RJ, and Kuligowski J. Adrenic acid non-enzymatic peroxidation products in biofluids of moderate preterm infants. Free Radic Biol Med 2019 [Epub ahead of print]; DOI: 10.1016/ j.freeradbiomed.2019.02.024.

7. Sánchez-Illana Á, Thayyil S, Montaldo P, Jenkins D, Quintás G, Oger C, Galano J-M, Vigor C, Durand T, Vento M, and Kuligowski J. Novel free-radical mediated lipid peroxidation biomarkers in newborn plasma. Anal Chim Acta 996: 88-97, 2017.

8. Vento M, Hummler H, Dawson J, Escobar J, and Kuligowski J. Use of oxygen in the resuscitation of neonates. In: Perinatal and Prenatal Disorders, edited byDennery PA, Buonocore G, and Saugstad OD. New York: Humana Press, 2014, pp. 213-244.

9. Villamor-Martínez E, Pierro M, Cavallaro G, Mosca F, Kramer BW, and Villamor E. Donor human milk protects against bronchopulmonary dysplasia: a systematic review and meta-analysis. Nutrients 10: pii: E238, 2018.
Address correspondence to:

Dr. Julia Kuligowski

Neonatal Research Group

Health Research Institute La Fe

Avenida Fernando Abril Martorell 106

Valencia 46026

Spain

E-mail: julia.kuligowski@uv.es

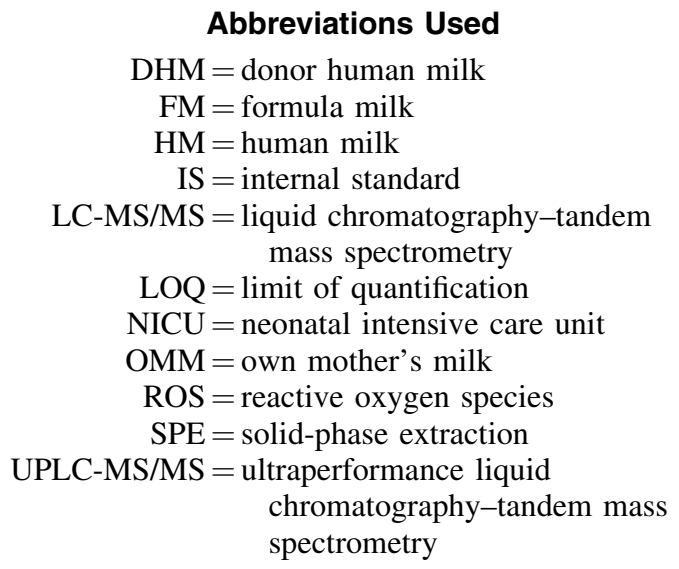

Abbreviations Used

$\mathrm{DHM}=$ donor human milk

$\mathrm{FM}=$ formula milk

$\mathrm{HM}=$ human milk

IS = internal standard

LC-MS/MS = liquid chromatography-tandem mass spectrometry

$\mathrm{LOQ}=$ limit of quantification

$\mathrm{NICU}=$ neonatal intensive care unit

$\mathrm{OMM}=$ own mother's milk

$\mathrm{ROS}=$ reactive oxygen species

$\mathrm{SPE}=$ solid-phase extraction

UPLC-MS/MS = ultraperformance liquid chromatography-tandem mass spectrometry 